(Uniwersytet Łódzki, e-mail: irena.jaros@uni.lodz.pl)

ORCID: 0000-0001-6397-5890

\title{
GALANTY I GALANCIE JAKO LEKSYKALNE WYKLADNIKI STOPNIA NATĘŻENIA CECHY W GWARACH I POLSZCZYŹNIE OGÓLNEJ
}

W polszczyźnie ogólnej oraz w gwarach funkcjonują leksykalne środki, za pomocą których możemy wyrażać różne wartości określanej cechy. Sa nimi najczęściej przysłówki (stopnia i jakościowe ${ }^{1}$ ) komunikujące o różnym stopniu natężenia cechy wyrażonej przez przymiotnik, np. bardzo głęboki, prawie pusty, całkiem ładny, lub przez czasownik informujacy o właściwościach, stanach podmiotu, np. bardzo smucić się, przeraźliwie sie nudzić, niezmiernie dziwić sie, oraz o ich nabywaniu lub nadawaniu, np. mocno się ubrudzić, bardzo przytyć [zob. Grzegorczykowa 1975, 37-38, 64-70]. Na grupę leksemów wskazujących na stopień natężenia cechy składają się zarówno środki określające intensywność cechy nazywane inaczej intensyfikatorami (np. bardzo, wielce, dalece) [zob. Janus 1981, 5, 15] lub jej brak (tzw. dezintensyfikatory, np. trochę, nieco), jak i szerzej - jej gradację wyrażająca kompletność (np. całkiem, zupełnie), niepełność lub wystarczająca ilość, dostateczność cechy (np. dość, dosyć, odpowiednio) oraz jej nadmiar (np. zbyt, zanadto) [Bałabaniak 2013, 68]. W polszczyźnie podobna funkcję moga spełniać również przymiotniki, które $\mathrm{np} . \mathrm{w}$ zestawieniach typu całe modre niebo, całe szerokie żelazo, cały drewniany pług oznaczają pełny stopień cechy [Osowski 2012, 94; KSGP PAN]. Znaczenie wyrażeń gradacyjnych ${ }^{2}$ mogą zachowywać niektóre przymiotniki w konstrukcjach typu kolosalny wysiłek, ogromny kłopot, szalony apetyt. ${ }^{3}$

Wśród różnorodnych leksykalnych wykładników gradacji cechy pojawiajacych się w gwarach i regionalnych odmianach polszczyzny ogólnej odnajdujemy przymiotnik galanty // galantny i pochodzace od niego

1 Zob. Grzegorczykowa 1975, 44.

2 Termin: wyrażenie gradacyjne za D. Bałabaniak [2013, 59] odnoszę do leksykalnych wykładników gradacji.

3 Elżbieta Janus traktuje tego typu przymiotniki i pochodzace od nich przysłówki jako wykładniki intensywności o różnej postaci formalnej [zob. Janus 1977; 1981]. Takim przymiotnikowym określnikom gradacji D. Bałabaniak przypisuje status „meta” i nazywa metapredykatorami przymiotnikowymi lub quasi-przymiotnikowymi, por. Bałabaniak 2013, 118-120. 
przysłówki: galancie, galańcio i galanto. Sa to leksemy o gwarowej proweniencji, znane na dość dużym obszarze Polski, rejestrowane przede wszystkim w Wielkopolsce, oprócz części południowej [zob. AJW, mp. 878, 879, cz. 2: 178-183], i w sasiadujacych $z$ nia gwarach dawnej ziemi sieradzkiej i łęczyckiej, na Kujawach [SGKuj], ziemi chełmińsko-dobrzyńskiej [Maciejewski 1969], na terenie Małopolski (przede wszystkim północnej) [por. AGK, mp. 498, SL] oraz sporadycznie na Mazowszu i na Śląsku [zob. SGŚ, SGP PAN]. Ich charakterystyczna cecha jest dość rozbudowana wieloznaczność, o czym przekonują dane zamieszczone w Slowniku gwar polskich [SGP PAN].

Podstawowe i prawdopodobnie prymarne znaczenie wyrazu galanty $\mathrm{i}$ jego rozszerzonego o pusty semantycznie formant - ny wariantu galantny [zob. Karaś 1959] w gwarach, tzn. „ładny, piękny, elegancki, zgrabny, porządny, grzeczny, uprzejmy", np. galanty x"opåk, Wilków, pow. kielecki; sprav'e sob'e galante ubrańe, Nadrybie, pow. łęczyński; kupiłym kaszkit, dołym śtyry złote. Zowszym [owszem] galanty, ino gniecie mnie w łysine, Morzysław, obecnie dzielnica Konina; to galynty byu ptok 'ładny', Sędzin, pow. aleksandrowski; galantny chuepok, galantno jevuxa, szamotulskie [SGP PAN]; to było galante ubranie na wyjście, Łabiszyn, pow. żniński [SGKuj]; Dziolche se szukot, zeby była galanto 'ładna', Topolice, pow. opoczyński [SGP PAN, SGM]; galanty 'schludny, ładnie ubrany' [Nowak 2012]; chłopak galantny, młody 'elegancki', Rembówko, pow. ciechanowski [KSGP PAN]; to ći ies galantny xop, Pilchowice, pow. gliwicki [SGŚ, X, 13]; $Z$ tego Hynusia taki galantny synek, śląskie [SGS, X, 13] oraz powstałego od niego przysłówka galancie // galanto 'ladnie, pięknie, porządnie, elegancko', np. galańce śe ubrau 'elegancko', Wilków, pow. kielecki; żebyś ty matko nie światowała to byłoby galańciéj 'piękniej' koło chałupy, ok. Kielc; bez to galáńce páchñe, Trzebina, pow. opoczyński [SGP PAN, SGM], galańce vyglůndo [AJW, cz. 2., 182]; galanto 'strojnie', ok. Knyszyna [Rembiszewska 2007, 145] wiąże się $z$ jego pochodzeniem. Jest to bowiem przymiotnik utworzony od rzeczownika galant' 'elegant' znanego w polszczyźnie od XVII w. [zob. Linde, Słstp, SW, SWil, ESJPXVII, Dor], który współcześnie traktowany jest jako wyraz przestarzały [PSWP], a oznacza człowieka „niesłychanie grzecznego i uprzejmego, szczególnie w stosunku do kobiet, przy tym modnego i eleganckiego". W gwarach polskich, zapewne pod wpływem tego znaczenia, galantem nazywano nie tylko człowieka dobrze ubranego, eleganckiego, por. galant - mocne vystroiiony, leszczyńskie [AJW, XI, 181, pkt 75]; ale ze ćeb'e tera ies galant, Pilchowice, pow. gliwicki [SGŚ, X, 12], ale także kawalera starającego się o rękę panny, konkurenta, ukochanego, por. miałach ja galantów, Śląsk Cieszyński, Mosty, cz. czeskiego Cieszyna; viźaúax će ze tfoiim galantym [SGŚ, X, 12, por. hasło galant w SGP PAN]; Zachciało sie

4 Jest to wtórne substantivum $z$ niem. galant 'dworny, uprzejmy' lub $z$ franc. 'wytworny, elegancki'. 
starej babie młodego galanta (...), Obrowo, pow. toruński [KSGP PAN, SGKuj]. Pozostałe znaczenia omawianych wyrazów i ich form wiążą się przede wszystkim $z$ informacją o dużym rozmiarze charakteryzowanych desygnatów, ludzi i rzeczy, ich ilości, czy dorodności, np. galanty uovez iuž uros [AJW, cz. 2, 180, pkt 55], wychował ojciec galantych dzieci 'dużo dzieci', Domaniewice, pow. łowicki [SGPKarł], galańce 'dużo' peńezy mau to se kupeu, Wilków, pow. kielecki; čšeba galanto śmetany 'dużo', Woźniki, pow. zduńskowolski [SGP PAN]; jak my mielim tych kartofli galancie, to trzy tygodnie kopalim, Gajówka, pow. włocławski [SGKuj] lub wskazują na stopień natężenia / nasycenia określanej przez nie cechy, zawsze pozytywnej, wartościowanej dodatnio.

Omawiane formy wyrazowe w tych samych znaczeniach funkcjonuja również współcześnie w polszczyźnie ogólnej, o czym przekonują dane zamieszczone w Narodowym Korpusie Języka Polskiego (NKJP), pochodzące $z$ literatury pięknej, prasy oraz rozmów internautów, np. Czarny mundur, włosy przylizane galanto i wasik ułożony [Daniel Odija, Kronika umarłych, 2010]; Powitał tym sposobem zacnie władce Franków, który takoż uczynił galanty 'piękny' pokłon [Krzysztof Rutkowski, Paryskie pasaże, "Gazeta Wyborcza", 1993]; Ze trzy lata temu prawie pół budynku się zawaliło. A taki był galanty przed wojna 'piękny, porządny' [„Dziennik Łódzki", 2001]; Sam zreszta także prezentował się galantnie 'ładnie' [„Dziennik Polski”, 2002]; i chłop taki galanty 'przystojny, ładny' stał przy niej [Rozmowa o figurze, \#kanal_mowiony]; no i galantny wobec kobitek 'szarmancki' [pl.soc.polityka, 2005]; Urodziłaś się 13, a tu taki galanty kawaler ci sie trafit [pl.soc.dzieci, 2005]; witając się, galantnie zasalutowat do czapki [pinezka.pl, 2006].

Szczególnie interesujące wydają się te znaczenia omawianych leksemów, które wynikaja nie tylko $z$ ich funkcji ograniczającej się do wyrażenia cech o charakterze jakościowym czy ilościowym, ale również precyzowania ich natężenia. Celem artykułu jest zwrócenie uwagi przede wszystkim na tę funkcję omawianych form w gwarach i polszczyźnie ogólnej. Przedmiotem analizy staną się te $z$ użyć leksemów galanty, galancie, galańcio, galanto, których eksplikacja znaczeń będzie mieściła się w szeroko pojętym zjawisku gradacji, obejmujacej trzy kategorie semantyczne: dostateczność, kompletność i intensywność [Bałabaniak 2013, 59-60].

Dane egzemplifikujące to zagadnienie pochodza $z$ dzieł publikowanych, tzn. ze słowników gwarowych [SGPKarł, SGP PAN, SGŚ, SGM, SGKuj, SL, Świderska 1929; Maciejewski 1969; Nowak 2012], monografii [Sobierajski 1952] i atlasów gwarowych [AJW] oraz niepublikowanych materiałów, przede wszystkim z kartoteki Słownika gwar polskich ${ }^{5}$

5 W celu pełniejszej egzemplifikacji niekiedy przytacza się przykłady $z$ kartoteki Słownika gwar polskich, mimo występowania kontekstów w artykułach hasłowych leksemów: galanty, galantny, galanto, galancio, galancie w SGP PAN. 
[KSGP PAN]. Zawarte w tych źródłach dane językowe pochodza $z$ dość rozległej cezury czasowej, sa datowane od końca XIX wieku [SGPKarł] po czasy współczesne [NKJP]. Nie sądzę jednak, by ta właściwość analizowanego materiału mogła przeszkodzić w omówieniu funkcji form galanty i galancie w polszczyźnie, nie wydaje się bowiem, by zróżnicowanie temporalne i terytorialne miało większy wpływ na ich wartość semantyczna. Współczesne przykłady funkcjonowania omawianych leksemów w funkcji gradacyjnej wyekscerpowano $z$ Narodowego Korpusu Języka Polskiego. Przy ich wyborze skupiono się na cytatach pochodzacych $z$ rozmów internetowych reprezentujacych przede wszystkim polszczyznę potoczna, w mniejszym zakresie zaś styl literacki i publicystyczny. Nie wykorzystano cytatów pochodzacych z Chłopów Władysława Reymonta, w których omawiane leksemy wystapiły wyjątkowo często, $z$ uwagi na ich dość liczna egzemplifikację $\mathrm{w}$ prezentowanych materiałach gwarowych.

\section{PRZYMIOTNIK GALANTY}

Przymiotnik galanty oprócz swoich podstawowych znaczeń, wynikajaccych $z$ sensu fundujacego go wyrazu motywacyjnego, czyli rzeczownika galant, służy w gwarach i polszczyźnie potocznej do wyrażania często skomplikowanych i trudnych do jednoznacznej identyfikacji treści. Zarówno Słownik gwar polskich, jak i Narodowy Korpus Języka Polskiego rejestrują szereg użyć tego przymiotnika, który wiąże się z rzeczownikami w celu ich dokładniejszej charakterystyki. Jego specyficzną właściwością jest to, że w jego strukturze semantycznej mieszcza się - obok komponentu wskazującego na stopień natężenia cechy, różne znaczenia, nieujawnione eksplicytnie, np. śećoki iuž galante 'dość duże', to ne potša ix pilnovać [Szym]; zupa galanta 'całkiem dobra' a zmywanie zrobimy maniana [NKJP, pinezka.pl, 2008]. Obok wyrażeń gradacyjnych dość / dosyć, całkiem pojawiaja się nazwy cech o wysokiej wartości, wynikające $z$ subiektywnej, pozytywnej oceny nadawcy, dotyczące rozmiaru, właściwości fizycznych (np. duży, ciężki, obfity), wyglądu (zgrabny, ładny), smaku (np. dobry) czy np. stanu zdrowia (zdrowy) opisywanej postaci lub przedmiotu. Funkcja przymiotnika galanty jako wykładnika natężenia cechy ujawnia się dopiero po wejściu w głąb jego struktury semantycznej, stąd tylko wyraźne sformułowanie jego definicji pozwala na odkrycie / odsłonięcie znaczenia gradacyjnego. Niestety nie jest to zadanie łatwe, bowiem dość często można spotkać się z pewnym problemem przy próbie interpretacji znaczenia omawianego przymiotnika. Kłopot $z$ jego wyjaśnieniem wynika $z$ tego, że jego semantyka wyrażona w zdaniu może wskazywać zarówno przeciętny stan określonej cechy, np. 'dobry': galanty śkolńik

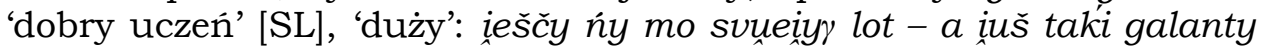
'duży', Chraplewo, pow. nowotomyski [AJW, cz. 2., 180, zob. Osowski 
2018, 104, 111], ${ }^{6}$ jak i poziom dostateczny, $z$ charakterystycznym dla tego typu gradacji określniku dość / dosyć, np. kamaše to mož iešče galante 'dosyć dobre', a ưubrańo ńi moš fcale [Szym]. Analiza zamieszczonych w źródłach definicji przymiotnika galanty nie ułatwia interpretacji jego znaczeń - często pojawiają się obok siebie różne pod względem wartości eksplikacje typu 'taki jak trzeba, dobry, porzadny, doskonały', 'duży, spory, wyrośnięty, dorodny' [SGP PAN, sv. galanty]. W związku z powyższym, w wypadku braku wyrażenia gradacyjnego w definicji znaczenia analizowanych przykładów oraz w odniesieniu do współczesnych cytatów, jesteśmy zmuszeni do dokonania arbitralnej oceny ich funkcji gradacyjnej na podstawie własnej kompetencji językowej.

Przykłady użyć przymiotnika galanty w gwarach pochodza przede wszystkim:

- z Wielkopolski, np.: galantygo vepška zabiliśta, 'dość dużego', Złotniki, pow. kaliski; galanty kavoueg drogi; galanty xuopok i inž zdatny do roboty; galante śvinaki urosuy; galante žyto; galante kartofle 'dość duży, spory' Kramsk, pow. koniński, galanty xlip ći śe udou 'dość dobry', galanto źeuxa s ty Ruśinuvny 'dość ładna' Kramsk, pow. koniński [SGP PAN; KSGP PAN];

- $\quad$ K Kujaw: miszkał un $z$ rodzina $w$ galantym dworku, naokoło którny byt duzy park, inowrocławskie; taki galanty kawolek, Szymborze, pow. inowrocławski [SGKuj];

- z ziemi chełmińsko-dobrzyńskiej: i iak iuš vyšly [kartofle] galante to potam uobuoryvaly ie; 'spore, dość duże' Siemoń, pow. toruński [Maciejewski 1969, 212];

- z ziemi łęczycko-sieradzkiej: plevńok, bo i̇už byu galanty 'dość duży, podrosły', Zagórzyce, pow. poddębicki [SL, sv. plewniak]; galanty 'dość duży, wyrośnięty', Rożniatów, pow. poddębicki; galanty kuńok se vyrobiu iešče s tego l'ixostfa 'dosyć duży'; galantom kobite sob́e znalos 'dosyć ładna'; galante śfyne porosuy 'dosyć ciężkie' [Szym];

- z północnej Małopolski, np. galanto j́ouxa 'dość ładna', Żychorzyn, pow. opoczyński [KSGP PAN]; žyće 'wyżywienie' to my dainum galante, ino robić tša duža 'obfite, dość duże', Trzebina, pow. opoczyński [SL, sv. $\dot{z} y c i e]$

- z Mazowsza: rośi galanti descik; 'dość duży', Janki Młode, pow. ostrołęcki; $Z$ drugi strony płotka tako galanto jałuwecka stojauxa 'wyrośnięta, dość duża' Łowickie; Prose tu do mńe, mum ja tu galanty towar na sprzedanie 'taki, jak trzeba, dobry', Czarnia, pow. ostrołęcki; Ach, co za galanty był już chłopiec, a madry nad komplet 'dość duży, spory', łukowskie, siedleckie [SGP PAN, KSGP PAN].

6 Pośrednio świadczą o tym utworzone od przymiotnika galanty derywaty informujące o wyższym poziomie natężenia cechy typu: galantawy 'dość duży, dość dobry' oraz ekspresywizmy: galańciutki, galańciuchny [SGP PAN, t. 8, z. 1.]. 
W gwarze Domaniewka, położonego w Łęczyckiem, M. Szymczak zanotował konstrukcje zdaniowe, w których formy dopełniacza wyrazu ga-

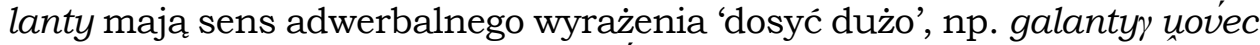
se doxovauy; galanty kuńcyny pšyv́uześ s tego kavouka; tag razem iego ii uoicuf to galanty źimi; galantygo žyta žeśta bez žin uumuućili [Szym]. Podobny przykład znajduje się w Słowniku gwar polskich J. Karłowicza [SGPKarł, t. II, 48]: wychował ojciec galantych dzieci, pochodzacy z Domaniewic w towickiem.

Jedynym odnalezionym przeze mnie przykładem gwarowym, w którym przymiotnik galanty bezpośrednio intensyfikuje cechę wyrażona innym przymiotnikiem jest wyrażenie: galanty uostry nus 'dostatecznie ostry', pochodzace $z$ Łowickiego [SGP PAN].

Przymiotnik galanty w omawianych przykładach informuje przede wszystkim o dostatecznym stopniu wyrażanej cechy. Podobnie należy interpretować przykłady zanotowane współcześnie, np. Wyszła z chaty góralka i przyniosła mi "taki galanty skopecek kwaśnego mlika" 'dość duży' [Justyna Bździuch, „Wychowawca” nr 199/200, 2009]; Uzbierałam już nawet galanty worek [chrustu] 'dosyć duży' [Irena Matuszkiewicz, Nie zabijać pajaków, 2007]; Zrobiła sie galanta zadyma, 'dosyć duża' [forumowisko.pl, 2005]; I krecha była galanta 'dość wyraźna' [pl.soc.dzieci, 2000]. Nieliczne przykłady dowodzą wyrażania przez przymiotnik galanty stopnia kompletności danej cechy, np. w zdaniu, pochodzacym z NKJP: zupa galanta 'całkiem dobra' a zmywanie zrobimy maniana [NKJP, pinezka.pl, 2008].

\section{PRZYSLÓWEK GALANCIE, GALANCIO, GALANTO}

Omawiane leksemy zarówno w gwarach, jak i w we współczesnej polszczyźnie należą do różnych kategorii semantycznych wyrażeń gradacyjnych. Podobnie jak w wypadku przymiotników, od których zostały utworzone, ich znaczenie nie zawsze jest wyrażone eksplicytnie, jest ukryte w głębi struktury semantycznej - obok określnika gradacji, np. dość / dosyć zawiera ona dodatkowe znaczenie. Informuja one przede wszystkim o stopniu dostateczności (wystarczalności) stanu lub czynności. ${ }^{7}$ Odnosząc się do jej przeciętnej wartości, wskazują na jej wystarcza-

7 Zdaniem D. Bałabaniak [2013, 121] „intensyfikatory wchodza w relacje tylko $z$ czasownikami, w których strukturze semantycznej jest jakiś element stopniowalny, nie łączą się zatem $z$ czasownikami oznaczającymi tylko akcję lub ruch”. „Łączenie się intensyfikatorów jedynie z elementem znaczenia danego czasownika (...) naśladuje semantyczną relację intensyfikatorów z przymiotnikami. Sens intensyfikatora aktualizuje się jakby wewnątrz danego predykatu" $[2013,122]$. 
jący ('taki jak trzeba', 'tyle, ile potrzeba', 'dogodny', 'dobry', 'w sam raz') poziom.

Dość dużo przykładów przysłówków galancie i galanto charakteryzujących czynność ze względu na jej dostateczność odnajdujemy w materiałach gwarowych, np.:

- z Wielkopolski: galańće 'tak jak trzeba, porządnie' pomalovou ta xysa 'dom', pow. kępiński; galańce ušyu [marynarkę] 'dobrze, tak, jak trzeba', pow. koniński [SGP PAN]; galańce se vlou 'wypił dość dużo alkoholu', galańce "uros 'sporo', galańce uiexali 'sporo', Sokołowo, pow. kolski [AJW XI, cz. 2., 182]; galańće uožes 'dość ładnie', galańće źiśei zuoroueś 'dość dużo', Kramsk, pow. koniński; powieda, że będzie galanto 'dobrze, jak trzeba' Aleksandrówek, pow. koniński, galańce se podioduym 'dobrze, tyle, ile trzeba', Złotniki, pow. kaliski [SGP PAN, KSGP PAN];

- z Kujaw: iåžym po ńimecku galańce rozumou 'dość dobrze, wystarczajacco', Kujawy [Sobierajski 1952, 89]; betków było galancie, inowrocławskie; galańće rozumioł, Bachorce, pow. inowrocławski 'dość dobrze'; ale galańće zjadłem 'dość dużo' Złotniki Kujawskie, pow. inowrocławski [SGKuj];

- $\quad$ z ziemi chełmińsko-dobrzyńskiej, np: ...ale kase iedly to una tam vyxó̉iua galańce 'sporo, dość dużo', Siemoń, pow. toruński [Maciejewski 1969, 211];

- z ziemi łęczycko-sieradzkiej, np.: Galańće mleka ńeśes 'dość dużo'; Copke barajkovom mou, galańće śe v ńi uxoźiu 'dość długo', Woźniki, pow. sieradzki [SGP PAN]; galańce zarobiueź na tym 'dosyć dużo'; galańce śe iuš popraviu po ty xorob'e 'dosyć dużo'; galańce śe iešče tšymo 'dosyć dobrze', galańce pofsxoźiuo iún to žyto 'dosyć dobrze' [Szym];

- z Małopolski: pšymrozek złapåł to tag beło galańći vyńś 'dogodnie, jak trzeba, dobrze', Radkowice, pow. starachowicki; zboże pięknie wymłócone (...), wszyćko galanto wymłynkowane 'tak jak trzeba', Iwkowa, pow. brzeski [SGP PAN]; galańce "okrośiuaś tyn bosz, bo ie taḱi dobry 'dość dużo, sporo', Trzebina, pow. opoczyński [SL, sv. okrasić]; galańce potsyxo to prańe; galańće mi śe xovo tyn prośok; galańco śnik pšysypou 'dobrze; dość dobrze; tak, jak trzeba' Studzienice, pow. pajęczański [SL, sv. podsychać, prosiak];

- z Mazowsza: Tam dużo Polaków jest. Polskie kościoly sum to i Polaków galancie jest 'sporo, dość dużo', Węgrzynowice, pow. tomaszowski [KSGP PAN], kunie już galancie przeżerły, ok. Przasnysza [KarłSGP]. Jedynym przykładem użycia przysłówka galancie bezpośrednio w funkcji określnika gradacji jest przykład pochodzacy $z$ Domaniewka w pow. łęczyckim: galańć dalekavo 'dosyć' [Szym] oraz z Lowickiego [Świderska 1929, 354].

Sporadycznie przysłówki galancie / galancio / galanto możemy odnaleźć w gwarach polskich w pozostałych funkcjach semantycznych charakterystycznych dla wyrażeń gradacyjnych - intensywności i kom- 
pletności. Pełnią one funkcję wykładnika wysokiego stopnia cechy stanu lub czynności nazwanych przez czasownik, zastępując ogólnopolski przysłówek bardzo i jego ekwiwalenty (mocno, znacznie) w zdaniach: $f$ sk ${ }^{u}$ ole galańce í xfalo 'bardzo', Wilków, pow. kielecki; Grabosḱi muśou śe galańce potuuc, že cauy tyźin ležy $v$ uušku 'bardzo', Kramsk, pow. koniński [SGP PAN; KSGP PAN]; Gołab, kowal wojkowski, galancie se podpit we Wlocinie $i$ szedt $w$ nocy do domu 'bardzo', Wojków, pow. sieradzki [KSGP PAN]; galańce pada desc ‘bardzo mocno' Dulsk, pow. golubsko-dobrzyński [Maciejewski 1969, 211]; "uno śe galańce "ućepleuo 'bardzo', Łowickie; [SGP PAN]; žyto galanće podrosto po tyx dyscax; galańce tšybum zaiunce f tym roku; galańco śniik pšysypou 'bardzo', Studzienice, Radom [SL, sv. podrastać, trzebić, przysypać]; ...i tégo mocno pob́uu, gal'anće 'bardzo', Kamianki-Wanki, pow. siedlecki [KSGP PAN]; Waleska zadowolo, że ja utoplec galanto 'mocno' wyściskoł, cisła ku swoji chałpie, śląskie [SGŚ, t. 10,13]. Omawiane przysłówki moga również pełnić rolę wykładnika kompletności odpowiadającego leksykalnym wyrażeniom gradacyjnym zupetnie i całkiem, np. galańce śe pšeiośniuxo 'całkiem', Studzienice, pow. pajęczański [SL, sv. przejaśnić się]; pšecykum śe, patše, rozvidńiuo śe galańće 'zupełnie', Rębowo, pow. płocki [SGP PAN].

Omówione funkcje przysłówków galancie / galancio / galanto jako wykładników gradacji właściwości charakteryzujących czynność lub stan wyrażone czasownikiem odnajdujemy również we współczesnej polszczyźnie ogólnej. W Narodowym Korpusie Języka Polskiego znajdują się cytaty potwierdzajace ich funkcję, polegajaca na informowaniu o wystarczajacym, dostatecznym poziomie cechy stanu lub czynności. Jako wykładniki gradacji reprezentują semantyczna kategorię dostateczności [Bałabaniak 2013, 59-61], np. już się tak galancie 'dość nisko' pochyliłem to pare razy tak czułem że ta [O sprzęcie narciarskim, \#kanał mówiony]; ale to tak na oko sie patrzy jak postawisz gdzieś przy grzejniku no żeby galancie 'dość wysoko, dobrze' wyrosło [O sprzęcie narciarskim, \#kanał mówiony]; a bo w piecu jeszcze galancie 'dość dużo' było [Rozmowy przy winie, \#kanał mówiony]; że galancie 'dość dużo' osób tam pojechało jakaś ekipa [Przyjaciółki-pogaduszki, \#kanał_mowiony]; Uciechy będzie moc, a imprez my tyz przyryktowali galancie 'dużo, dosyć dużo’! [„Gazeta Krakowska”, 2003]; znaczy się mleczaki 'zęby mleczne' trzymaja się galancie 'dość dobrze' [forum.michalkiewicz.pl, 2008].

Przysłówki te moga również pełnić rolę wykładnika intensywności, wskazuja bowiem na wysoki stopień cechy wyrażonej przymiotnikiem lub właściwości związanej $z$ określanym stanem lub czynnością, np. że jak masz kurcze ten stok galancie 'bardzo' waski, to musisz uważać nie? [O sprzęcie narciarskim, \#kanał mówiony]; U mnie galanto 'bardzo, w wysokim stopniu' spowalnia to działanie przegladarki [pl.rec.gory, 2002]; który estetycznie nic nie daje, za to galanto 'bardzo' pogarsza czytelność tekstu na nim [pl.rec.gory 2002]; Może nie tyle o niego co o 5 hektarów pasujacych „galantnie” 'bardzo', bo tylko za miedza leżacych [„Dziennik Polski”, 
1999]; Jeśli tak samo jest na ścieżce poniżej śnieżnych kotłów, kamloty moga być galanto 'bardzo, w wysokim stopniu' oblodzone... [pl.rec.gory, 2002]; ale masz galancie 'bardzo wysoko' ubezpieczony czy tylko tak średnio? [Rozmowy przy zwożeniu długich snopków, \#kanał mówiony]; Tam to się można dopiero galanto 'bardzo' zapocić... [pl.rec.gory, 2008]; że ten Pierdziwół skadś tam dawno już nie miał tak galancie 'bardzo' rozbitego łba [Witold Turant, Przygoda na Tylnej Mariackiej, 2009].

Przymiotnik galanty oraz pochodzace od niego przysłówki jako leksykalne wykładniki gradacji cechy pełnia wyjątkowa funkcję w polszczyźnie - za ich pomocą można sprecyzować stopień natężenia cechy od jej wartości przeciętnej, przez dostateczna, wystarczająca, kompletna po wysoką. Dzięki złożonej strukturze semantycznej, zawierającej obok elementu intensyfikującego różne sensy, wydobywane każdorazowo podczas ich aktualizacji w zdaniu, zyskuja uniwersalny charakter. Słowa galanty / galancie moga wszak wyrażać różne wartości wielu cech o charakterze stopniowalnym, a odczytanie znaczeń omawianych form jako wykładników intensywności cechy jest uwarunkowane kontekstowo. Możliwe, że ta ich właściwość, w dużym stopniu wygodna, wpisująca się w zasadę ekonomii w języku, decyduje o współczesnym utrzymywaniu się omawianych leksemów nie tylko w gwarach, ale również (a może przede wszystkim) w potocznej polszczyźnie ogólnej, ograniczonej terytorialnie. Można zdefiniować je jako regionalizmy o dialektalnym rodowodzie, znane sa bowiem nie tylko użytkownikom gwar ludowych, ale również mieszkańcom miast i miasteczek znacznego obszaru Polski [zob. SŁódź, 198, SłPoznań], którzy za ich pomoca dokonuja oceny wartości charakteryzowanych przez nich ludzi, przedmiotów i ich cech, czynności i stanów.

\section{Bibliografia}

AGK - K. Dejna, 1962-1968, Atlas gwarowy województwa kieleckiego, t.1-6, Łódź.

AJW - Z. Sobierajski, J. Burszta (red.), 1979-2005, Atlas języka i kultury ludowej Wielkopolski, t. 1-11, Wrocław-Poznań.

D. Bałabaniak, 2013, Polskie intensyfikatory leksykalne na tle wyrażeń gradacyjnych, Opole.

Dor - W. Doroszewski (red.), 1957-1969, Słownik języka polskiego, t. 1-10, Warszawa.

ESJPXVII/XVIII - Elektroniczny słownik języka polskiego XVII i I poł. XVIII w., on-line [dostęp: 31.07.2019].

E. Janus, 1981, Wykładniki intensywności cechy (na materiale polskim $i$ rosyjskim), Wrocław-Warszawa-Kraków-Gdańsk. 
E. Janus, 1977, Wykładniki intensywności cechy we współczesnej polszczyźnie, „Polonica” III, s. 47-57.

M. Karaś, 1959, O strukturach słowotwórczych typu białny, którny $w$ języku polskim, „Biuletyn Polskiego Towarzystwa Językoznawczego” t. XVIII, s. $113-135$.

KSGP PAN - kartoteka słownika gwar polskich: online http://rcin.org.pl/dlibra/ [dostęp: 22.07.2019].

L - S.B. Linde, 1854-1860, Słownik języka polskiego, t. 1-6, Lwów.

J. Maciejewski, 1969, Słownik chełmińsko-dobrzyński, Torun.

NKJP - Narodowy Korpus Języka Polskiego, online: www.nkjp.uni.lodz.pl [dostęp: 21.07. 2019].

J.K. Nowak, 2012, Słownik gwary górali żywieckich, Żywiec-Grojec-Warszawa.

B. Osowski, 2012, Morfologiczne i leksykalne wykładniki gradacji cechy wyrażonej przymiotnikiem w języku mieszkańców dwóch miejscowości $w$ Wielkopolsce, „Poradnik Językowy” z. 8, s. 71-97.

B. Osowski, 2018, Kategoria przymiotnika w języku mieszkańców wsi pótnocno-wschodniej i południowo-zachodniej Wielkopolski. Studium leksykalno-słowotwórcze, Poznań.

PSWP - H. Zgółkowa (red.), 1994-2005, Praktyczny słownik współczesnej polszczyzny, t. 1-50, Poznań.

D.K. Rembiszewska, 2007, Słownik dialektu knyszyńskiego Czesława Kudzinowskiego, Łomża.

SGM - J. Wronicz (red.), 2016, Słownik gwar małopolskich, t. I, Kraków.

SGP PAN - Słownik gwar polskich [A - Hyżki], 1977-, oprac. przez Zakład Dialektologii Polskiej Instytutu Języka Polskiego PAN, Źródła i t. I, red. M. Karaś, J. Reichan; t. II-V, red. J. Reichan, S. Urbańczyk, t. VI, red. J. Okoniowa, J. Reichan, t. VII-, red. J. Okoniowa, J. Reichan, B. Grabka, Wrocław-Warszawa-Kraków-Gdańsk-Łódź.

SGPKarł - J. Karłowicz: Słownik gwar polskich, 1900-1911, t. 1-6, online: http:/ /zbc.uz.zgora.pl/dlibra/ [dostęp: 21.07.2019].

SGKuj - Z. Sawaniewska-Mochowa (red.), 2017, Słownik gwary i kultury Kujaw, t. 1: $A-H$, Bydgoszcz.

SGŚ - B. Wyderka (red.), 2008, Słownik gwar śląskich, t. 10, Opole.

SL - K. Dejna, 1974-1985, Słownictwo ludowe z terenu województw kieleckiego $i$ łódzkiego, „Rozprawy Komisji Językowej Łódzkiego Towarzystwa Naukowego" $(A-B) 1974,20$, s. 189-277; $(C-D)$, 1975, 21, s. 135-290; tegoż: Słownictwo ludowe $z$ terenu byłych województw kieleckiego i łódzkiego, „Rozprawy Komisji Językowej Łódzkiego Towarzystwa Naukowego" (E-J) 1976, 22 , s. $135-268 ;(K), 1977,23$, s. 147-290; $(L-M) 1978,24$, s. 149-274; (N-Ó), 1979, 25, s. 123-276; (Pa-Por) 1980, 26, s. 117-257; (Pos-R), 1981, 27, s. 129-281; (Sa-Sy) 1982, 28, s. 119-261; (Sz-U) 1983, 29, s. 83-233; (W), 1984, 30, s. 91-213; (Z-Z்), 1985, 31, s. 143-265.

SŁódź - D. Bieńkowska, M. Cybulski, E. Umińska-Tytoń, 2007, Słownik dwudziestowiecznej Łodzi. Konteksty historyczne, społeczne, kulturowe, Łódź.

SłPoznań - M. Gruchmanowa, B. Walczak, Słownik gwary miejskiej Poznania, online: http://www.poznan.pl/mim/slownik/ [dostęp: 25.07.2019 r.].

Słstp - S. Urbańczyk (red.), 1956-1959, Słownik staropolski, t. 2 (D-H), Wrocław. Z. Sobierajski, 1952, Gwary kujawskie, Poznań. 
SW - J. Karłowicz, A. Kryński, W. Niedżwiedzki (red.), 1900-1927, Słownik języka polskiego, t. 1-8, Wrocław-Warszawa.

SWil - A. Zdanowicz i in. (red.), 1861, Słownik języka polskiego, t. 1-2, Wilno, online: http:/ / eswil.ijp-pan.krakow.pl/ [dostęp: 25.07.2019].

SzymDom - M. Szymczak, 1962-1973, Słownik gwary Domaniewka w powiecie łęczyckim, cz. 1-8, Wrocław.

H. Świderska, 1929, Dialekt Księstwa Łowickiego, „Prace Filologiczne” t. 14, s. $257-413$.

\section{Galanty and galancie as lexical exponents of the intensification degree of a characteristic in dialects and general Polish}

\section{Summary}

The author presents the functions of the lexical exponents of gradations with a dialectal origin, namely of: the adjective galanty and the averbs galancie, galancio, galanto in the colloquial Polish language and Polish dialects. Based on dialectal and general Polish data coming from published works (dictionaries, atlases, dialectal monographs) and unpublished collections of vocabulary, she discusses their gradational meanings falling into three semantic categories: sufficiency (e.g. galancie osób pojechało ('quite many' people have gone)), completeness (e.g. zupa galanta ('quite a good' soup)), and intensity (e.g. galancie waski (a 'very' narrow)). The identification of the meanings of the discussed forms as exponents of the intensity of a characteristic is, in most cases, conditioned on the context. They express various values of many gradational characteristics which are extracted while being actualised in a sentence. Due to their limited distribution (mainly Greater Poland, Kuyavia, Łęczyce and Sieradz Land, northern Lesser Poland, Masovia, Chełmno and Dobrzyń Land) and presence in the colloquial Polish language, the discussed forms can be classified as regionalisms with a dialectal origin.

Keywords: lexicology - dialectology - dialects - colloquial Polish language regionalisms 